\title{
O EFÊMERO NOS SUBÚRBIOS DA CIDADE DO RIO DE JANEIRO: MICROPRÁTICAS DE RESISTÊNCIA
}

\section{El efímero en los suburbios de la ciudad de Rio de Janeiro: Micro-prácticas de resistencia.}

The ephemeral in Rio de Janeiro's suburbs:

Micro-practices of resistance.

María Paula Gonçalves Lysandro de A.

Professora Associada Faculdade de Arquitetura e Urbanismo - Docente Permanente Programa de Pós-Graduação em Urbanismo. Universidad Federal do Río de Janeiro. Río de Janeiro. Brasil.

mpaula.albernaz@gmail.com

https://orcid.org/0000-0002-1975-8490

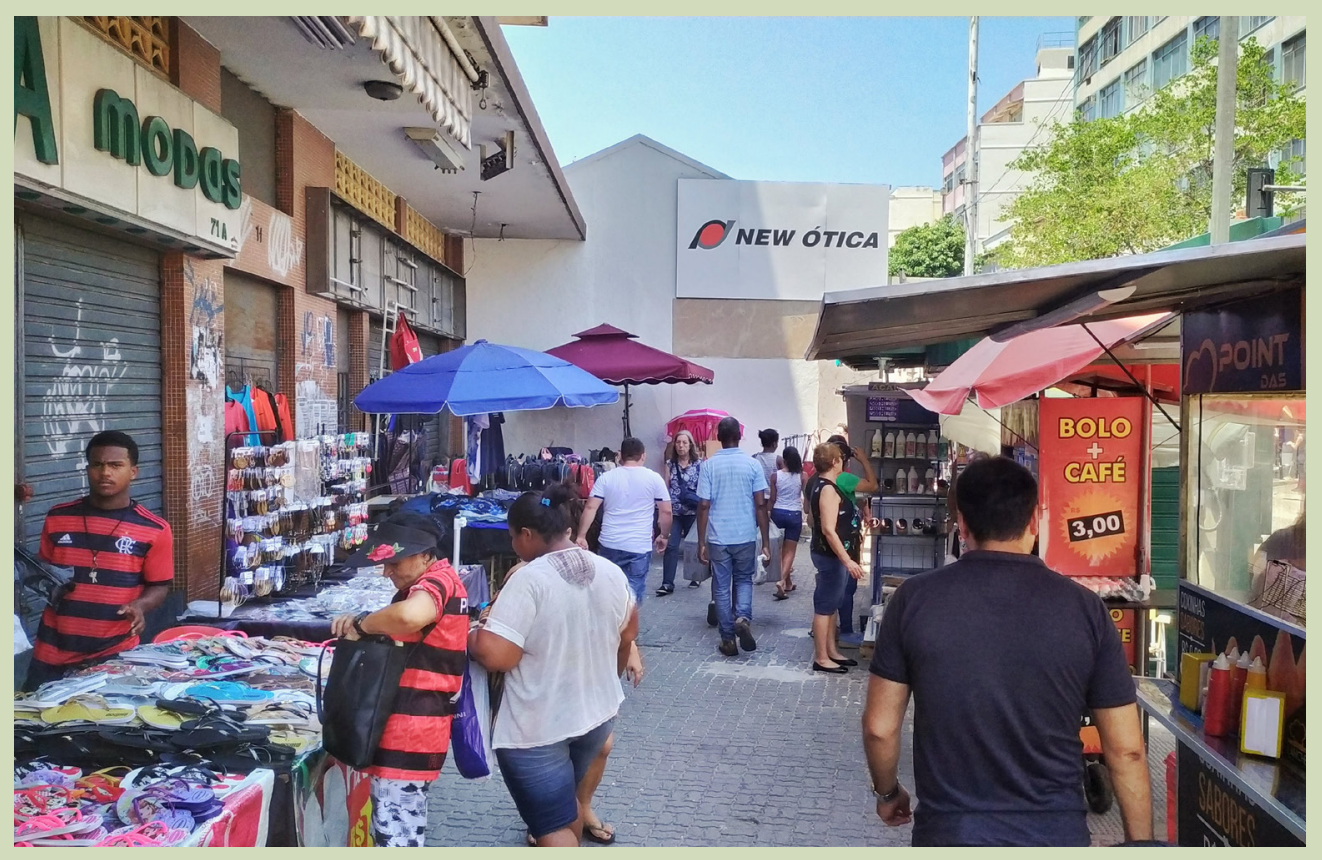

Proyecto:

Fundação de Amparo à Pesquisa do Estado do Rio de Janeiro FAPERJ, Conselho Nacional de Desenvolvimento Científico e Tecnológico - CNPq e Universidade Federal do Rio de Janeiro UFRJ

o efêmero nos subúrbios cariocas. Fonte: Bárbara Boy 


\section{RESUMO}

Este artigo apresenta situações de natureza efêmera adotadas na apropriação do espaço público de Olaria, Ramos e Bonsucesso, subúrbios da cidade do Rio de Janeiro. Essas situações revelaram-se no âmbito do ensino do projeto urbano no curso de arquitetura e urbanismo, motivado pela preocupação com uma atuação condizente com as complexidades da cidade contemporânea. Nossa abordagem investigativa partiu da análise espacial na escala microlocal que melhor permite observar efeitos da forma urbana para aqueles que a vivenciam diariamente, considerando a relação entre materialidades e eventos cotidianos. $O$ conceito da singularidade compreendido como potência resultante da inventividade ao se adaptar à condição urbana dominada por processos hegemônicos, criadora de diversidade no ambiente urbano e permanência de agentes locais no lugar, serviu de suporte teórico à pesquisa. Por apresentarem-se múltiplas situações singulares efêmeras, incorporamos ao quadro teórico-metodológico, o conceito de arquitetura efêmera entendida (assim como o efêmero) como espacialidade transitória, orgânica e flexível, envolvendo baixos recursos financeiros e humanos, e ações vindas "de baixo para cima", mas (distintamente deste) igualmente como concepção capaz de gerar qualidade ambiental e urbana. Comparadas a exemplos estudados de 'micropráticas', avaliamos haver uma distinção nas situações efêmeras dos subúrbios cariocas, por abarcarem uma dimensão econômica e social. Esta condição abre uma perspectiva para a arquitetura efêmera colaborar na inclusão socioespacial urbana. Há desafios a enfrentar incluindo a dificuldade do desenho urbano em lidar com a informalidade, a vulnerabilidade social, a degradação ambiental e paisagística, a infraestrutura precária. Neste sentido, há que considerar: criar um sistema de regras de desenho associadas coletivamente ao projeto para orientar a apropriação espacial; ordenar o uso do espaço público por atividades do âmbito privado e o compartilhamento de práticas do trabalho com os fluxos da circulação; além da adoção de soluções para temporalidades diferenciadas representadas por uma reinstalação diária de dispositivos.

Palavras chave: análise urbana, arquitetura efêmera, áreas suburbanas, espaço público, arquitetura espontânea.

\section{RESUMEN}

Este artículo presenta situaciones de naturaleza efímera adoptadas en la apropiación del espacio público de Olaria, Ramos y Bonsucesso, suburbios de la ciudad de Rio de Janeiro. Esas situaciones se revelaron en el contexto de la enseñanza del diseño urbano en el curso de arquitectura y urbanismo, motivado por una actuación coherente con las complejidades contemporáneas. Nuestra investigación empezó por el análisis espacial micro-local, que permite observar los efectos de la forma urbana para aquellos que la viven diariamente, considerando la relación entre materialidades y eventos cotidianos. El concepto de singularidad entendido como potencia inventiva de adaptación a la condición urbana dominada por procesos hegemónicos, creadora de diversidad en el entorno urbano y permanencias para los agentes locales, sirvió de referencia teórica. Debido a las múltiples situaciones singulares efímeras, incorporamos al cuadro teórico el concepto de arquitectura efímera entendida (como el efímero) como espacialidad transitoria, orgánica y flexible, que implica bajos recursos financieros y humanos y acciones de "abajo hacia arriba", pero (distinto de este) también como una concepción que genera calidad urbana y ambiental. En comparación con los ejemplos de micro prácticas ya estudiados, consideramos la peculiaridad de las situaciones efímeras de los suburbios cariocas, debido a la incidencia de dimensiones económicas y sociales. Esto abre una perspectiva para la colaboración de la arquitectura efímera en la inclusión socioespacial urbana. Existen desafíos, incluida la dificultad del diseño urbano de hacer frente a la informalidad, la vulnerabilidad social, la degradación ambiental y la precariedad de infraestructura. Por eso es necesario considerar: la creación de un sistema de reglas de diseño asociadas al proyecto para guiar la apropiación espacial; la ordenación del espacio público por actividades privadas y el intercambio de prácticas laborales con flujos de circulación; la adopción de soluciones para distintas temporalidades resultantes de la reinstalación diaria de dispositivos.

Palabras clave: análisis urbano, arquitectura efímera, áreas suburbanas, espacio público, arquitectura espontánea.

\section{SUMMARY}

This article looks at ephemeral situations adopted in the appropriation of public spaces in Olaria, Ramos and Bonsucesso, suburbs of the city of Rio de Janeiro. These situations were revealed in the context of teaching Urban Design in the Architecture and Urbanism course, motivated by concerns about a coherent intervention that considers the city's contemporary complexities. Our approach stemmed from a spatial analysis on a micro scale, that allows observing the effects of Urban Form for those who experience it, considering the relationship between materiality and daily events. The theoretical basis of the research is the concept of singularity, understood as the result of inventiveness to adapt to the urban condition, dominated by hegemonic processes, which creates density in the urban environment and permanence for local agents. Given the multiple ephemeral singular situations found in our investigation, we also incorporated the concept of ephemeral architecture into our theoretical-methodological framework as a fleeting, organic and flexible spatiality, that requires few financial or human resources, and relies on bottom-up action. In contrast, with the already studied micro-practices, we consider the peculiarity of ephemeral situations in Rio de Janeiro's suburbs involving socioeconomic characteristics. This opens the door for ephemeral architecture to contribute towards urban social and spatial inclusion. For that reason, however, we must consider the difficulty for Urban Design to deal with informality, environmental and landscape decay, as well as precarious infrastructure. For that reason, it is important to include a system of design rules to guide spatial appropriation, organizing public space by private activities and the exchange of working practices with circulation flows, as well as adopting solutions to deal with the daily reinstallation of devices. 


\section{INTRODUÇÃO}


ARQUITECTURA EFÍMERA

Figura 1

Detalhe do mapa da cidade do Rio de Janeiro, mostrando subúrbios de Olaria, Ramos e Bonsucesso, objeto de análise. Fonte: Caroline Oishi área próxima ao campus universitário, na llha do Fundão, além de ser menos estudada no campo do urbanismo e arquitetura [Figura I]. Neles buscamos constatar as especificidades que fizeram com que fossem considerados em conjunto o quarto centro de maior relevância regional em recente instrumento de planejamento metropolitano (Câmara Metropolitana de Integração Governamental, 2015).

A abordagem da investigação partiu da análise do ambiente urbano privilegiando a relação entre as formas físicas e as dinâmicas sociais, ou seja, entre as materialidades e os eventos, que nos remete à especificidade da arquitetura no estudo urbano, e nos permite entender os efeitos trazidos para aqueles que vivenciam a forma urbana (Solà-Morales, 2008). Este viés é complementado pela prioridade dada à microescala que melhor permite observação da variedade e intensidade de ações e dinâmicas possibilitadas pela experiência nas espacialidades que afetam o cotidiano (Habraken, 1998; Panerai, 2006). A partir, optamos por levantar as peculiaridades referentes às formas de habitar, aos modos de vivenciar os espaços e às marcas de um passado ainda presente na paisagem.

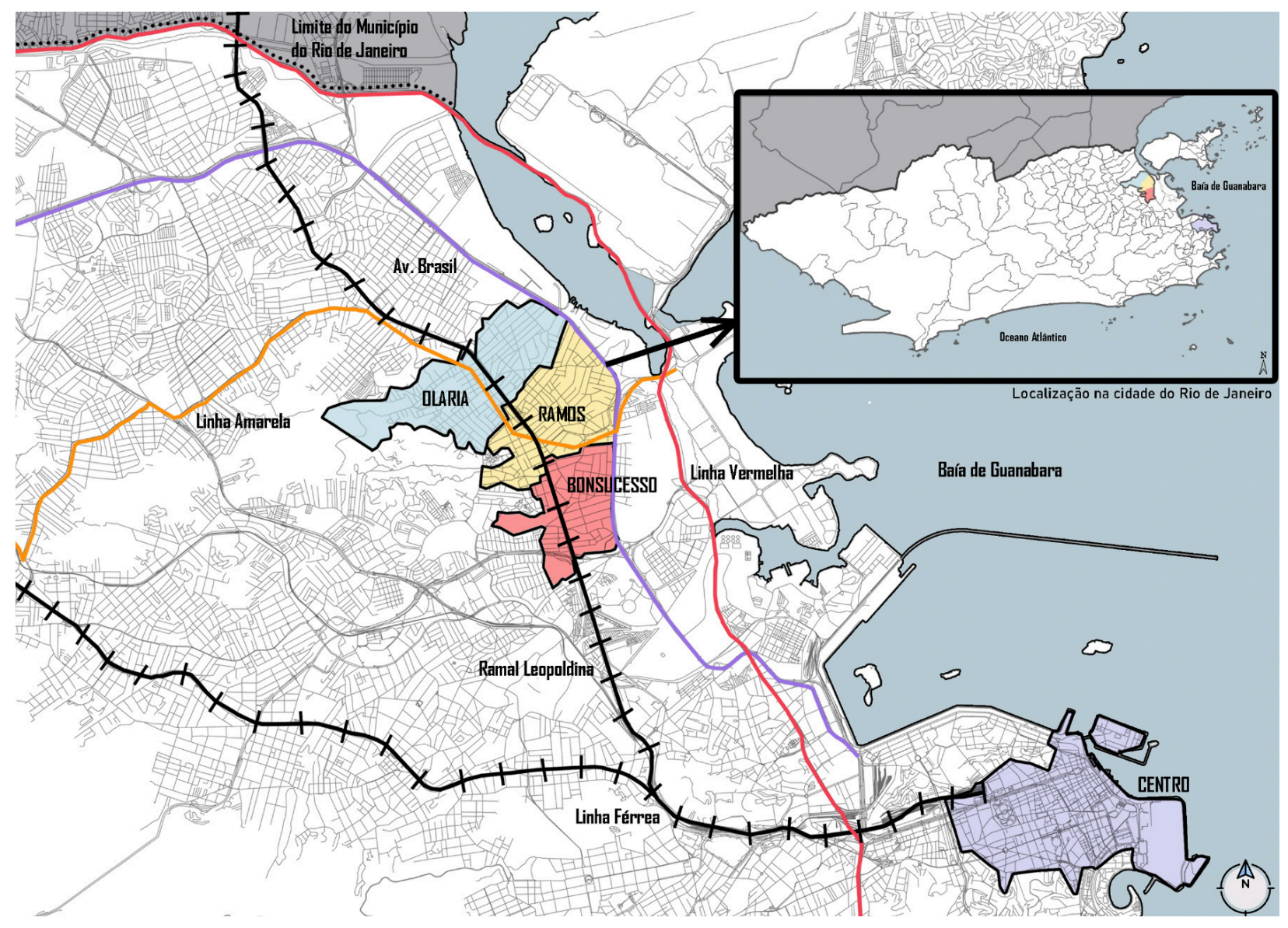




\section{O CONCEITO DE SINGULARIDADE}


Com uma abordagem distinta e uma visão atrelada à militância política os filósofos Michel de Certeau (2014) e Félix Guattari (Guattari \& Rolnik, 1996) igualmente colocam um posicionamento que se opõe ao generalizado prevalecente do hegemônico. A oposição a este universal caracteriza-se pela captação de elementos da situação sem embates, apenas com o aproveitamento de condições favoráveis. A partir daí, propõe-se, com liberdade, à revisão de seus processos e à construção de suas próprias referências, estabelecendo uma possibilidade de criação e de preservação de caráter autônomo.

Para Certeau (20 I 4), a oposição é identificada com a 'tática' através da qual se garantem "continuidades formais e permanência de uma memória sem linguagem". A tática é responsável pela constituição de "achados alegres, poéticos", "gestos hábeis". Reconhece a possibilidade de sua multiplicação pela ampliação de uma textura cada vez mais fina da condição de generalidade. Identifica a necessidade de investigação desses movimentos, questionando acerca de sua origem e do seu devir.

A 'singularização', como identificado esse contraponto por Guattari (Guattari \& Rolnik, 1996), trata-se de "processos disruptores no campo da produção do desejo", "produção de subjetividades originais e singulares", "através da afirmação de outra maneira de ser, outras sensibilidades, outra percepção". Nela se vislumbra atributos o "calor nas relações", uma "determinada maneira de desejar", uma "afirmação positiva da criatividade". Torna possível estabelecer condições diferentes de vida coletiva e desencadear reapropriação de territórios subjetivos.

Os subúrbios da Cidade do Rio de Janeiro podem hoje referir-se a territórios que abrigam uma multiplicidade de manifestações e expressões singulares vinculadas ao lugar, com a participação de variados agentes locais, ilustrando uma rica cultura urbana nem sempre reconhecida e pormenorizada em suas individualidades. Correspondem às maneiras de agir e interagir próprias de moradores e frequentadores que conformam, impedem ou propiciam práticas sociais ligadas a concepções de mundo e costumes localmente enraizados e orgânicos. Frequentemente, dizem respeito a ações e atuações espontâneas, transitórias e intermitentes, identificadas com o efêmero, que se contrapõem às tendências da rigidez e predeterminações do mundo globalizado atual. Neste sentido, precisam ser conhecidas tanto por quem tem como função planejar como projetar a cidade como por quem as vivencia.

\section{O CONCEITO DE EFÊMERO}

Efêmero significa aquilo que tem curta duração, que é breve, transitório; que possui caráter temporário (Houaiss, 200 I). Ao lidar com a efemeridade em termos urbanísticos e arquitetônicos, significa prever uma existência material e espacial restrita a certo período de tempo, mesmo que não haja uma determinação de durabilidade para caracterizá-la (Balem, 2017). Importante ressaltar que provisório não significa precário, podendo mesmo implicar complexidades construtivas e de 
organização espacial maiores. Na arquitetura e urbanismo efêmero, destacam-se dois aspectos: (a) a primazia da dimensão temporal dentre as demais envolvidas (Bishop \& Williams, 2012), que the atribui o próprio caráter da transitoriedade; (b) a prevalência dos eventos, ou seja, das ações de pessoas, na constituição da espacialidade (Sánchez, 2015), por sua natureza orgânica e flexível.

A arquitetura e urbanismo efêmero, por se tratar de uma materialidade que ocupa o espaço já com uma intencionalidade de ser retirada, exige primordialmente um resultado temporal, mas requer também efeitos satisfatórios técnicos, funcionais e simbólicos. No que diz respeito à dimensão técnica, o critério básico a ser levado em consideração na arquitetura efêmera, é a introdução de sistemas construtivos ágeis, que permitam rápida e fácil montagem e desmontagem. Neste sentido, interessa a tecnologia que possibilita a ocupação e a desocupação espacial em menor período de tempo.

No envolvimento da dimensão funcional, o desempenho de atividades na arquitetura efêmera tem de ser com o máximo de eficiência no tempo, pois se dá com uma duração limitada. Por não estar permanentemente no espaço, pode ter sua imagem descolada da paisagem que a involucra. No entanto, por não ser permanente, requer maiores esforços para que se torne percebida e as pessoas sintam por ela, empatia (Sánchez, 20 I5).

Em relação ao destaque aos eventos na arquitetura efêmera, importa, sobretudo, a configuração, ou seja, a composição de todas as suas partes materiais (Habraken, 1998). A configuração pode se dar de muitos modos, dependendo da escala do que se observa. Pode incluir, por um lado, os edifícios e as áreas livres do entorno; por outro, o mobiliário, artefatos e outros elementos de pequena escala que se percebe. Mas, o mais importante na configuração são as ações humanas. Através delas percebemos a versatilidade que o espaço oferece. Assim, nas duas perspectivas citadas, para criação de uma arquitetura e um urbanismo efêmero há principalmente que se considerar a temporalidade, ou seja, o tempo de sua duração, e o público a quem atenderá.

Vale ainda pensar na tecnologia envolvida, as que possibilitam agilidade, e em soluções espaciais e imagéticas flexíveis, versáteis e potentes. Há ainda a considerar para sua compreensão a condição que oferecem relativa à diminuição de recursos a serem disponibilizados (Bishop \& Williams, 2012). Neste sentido, têm um grande apelo ao apresentar oportunidades de redução de aportes financeiros e humanos, assim propiciando aumento do número daqueles que podem se envolver com a sua execução. Por fim cabe citar um aspecto proveniente do debate em torno do urbanismo tácito, mas que pode ser referida à efemeridade, relativa ao potencial na configuração da paisagem urbana de iniciativas na microescala, com base em práticas sociais e apropriações coletivas, em se constituir ações vindas de baixo para cima (Rosa, 2011). 


\section{A REGIÃO DA LEOPOLDINA E SUAS SINGULARIDADES}

Como muitos outros subúrbios cariocas, a região da Leopoldina incluindo Olaria, Ramos e Bonsucesso, tem sua paisagem moldada pela presença da linha e paradas do trem, além da vertente de morros (Albernaz, 2019b). Diferentemente de outros, teve seu território marcado por uma proximidade com a orla da baía de Guanabara que ao longo do tempo foi se perdendo, em decorrência de aterros para inicialmente implantar a Avenida Brasil, e depois, intensificação da ocupação por favelas que se aproveitaram do aterramento de áreas antes alagáveis. A presença de estruturas fabris ao longo da Avenida Brasil, na zona industrial demarcada junto à via, é outra especificidade.

Essas condições geográficas e processos históricos particulares hoje se revelam no desenho de sua trama urbana através da fragmentação do tecido urbano e linearidade das relações socioespaciais [Figura I] que influenciam os atributos de suas singularidades. As interrupções no tecido urbano representam dificuldade maior na irradiação de dinamismo urbano, que tende a ser linear e dependente do fluxo de passagem e paradas dos modais de transporte. $\bigcirc$ único ponto onde a vitalidade urbana é radial é nos locais de possível "costura" do tecido urbano, ou seja, os atravessamentos da linha férrea, junto às estações de trem. Verifica-se uma tendência a uma rígida separação de distintas faixas tipomorfológicas, que por sua vez, se organizam diluindo fronteiras entre bairros vizinhos [Figura 2].

O resultado é uma vitalidade urbana desigual nos centros de Olaria, Ramos e Bonsucesso, em relação aos lados da linha férrea, subordinada à presença não só das estações de trem, mas de paradas de ônibus com maior número de linhas, equipamentos de grande porte, áreas mais densas de moradia, ou mais recentemente do terminal do BRT, acarretando um fluxo maior de transeuntes. Estar nos eixos de passagem ou em suas cercanias, do lado mais dinâmico da linha férrea, é crucial para o comércio. Neste sentido, surgem situações singulares de caráter efêmero, associadas ao comércio formal ou informal, ligadas ao aproveitamento de oportunidades que a linearidade oferece.

Do mesmo modo, a linearidade e fragmentação do tecido urbano, acabaram resultando, particularmente em Ramos, em um esvaziamento das atividades comerciais do seu centro. Hoje a tendência é da absorção desse centro - cujas atividades se transferiram para esquinas de ruas transversais à linha férrea - pelo centro de Olaria. A não utilização ou subutilização de edifícios nas proximidades das estações de trem revelam-se igualmente como uma chance para instalação de situações singulares efêmeras.

Outro aspecto do legado da formação urbana de Olaria, Ramos e Bonsucesso, para as situações singulares efêmeras, diz respeito ao parcelamento urbano decorrente da presença do transporte ferroviário. A expectativa de ganhos com a venda de terrenos com facilidades de acesso em terras ainda rurais, apesar de em um momento de crescimento da cidade, fez com que mais do que em outros subúrbios, esses 


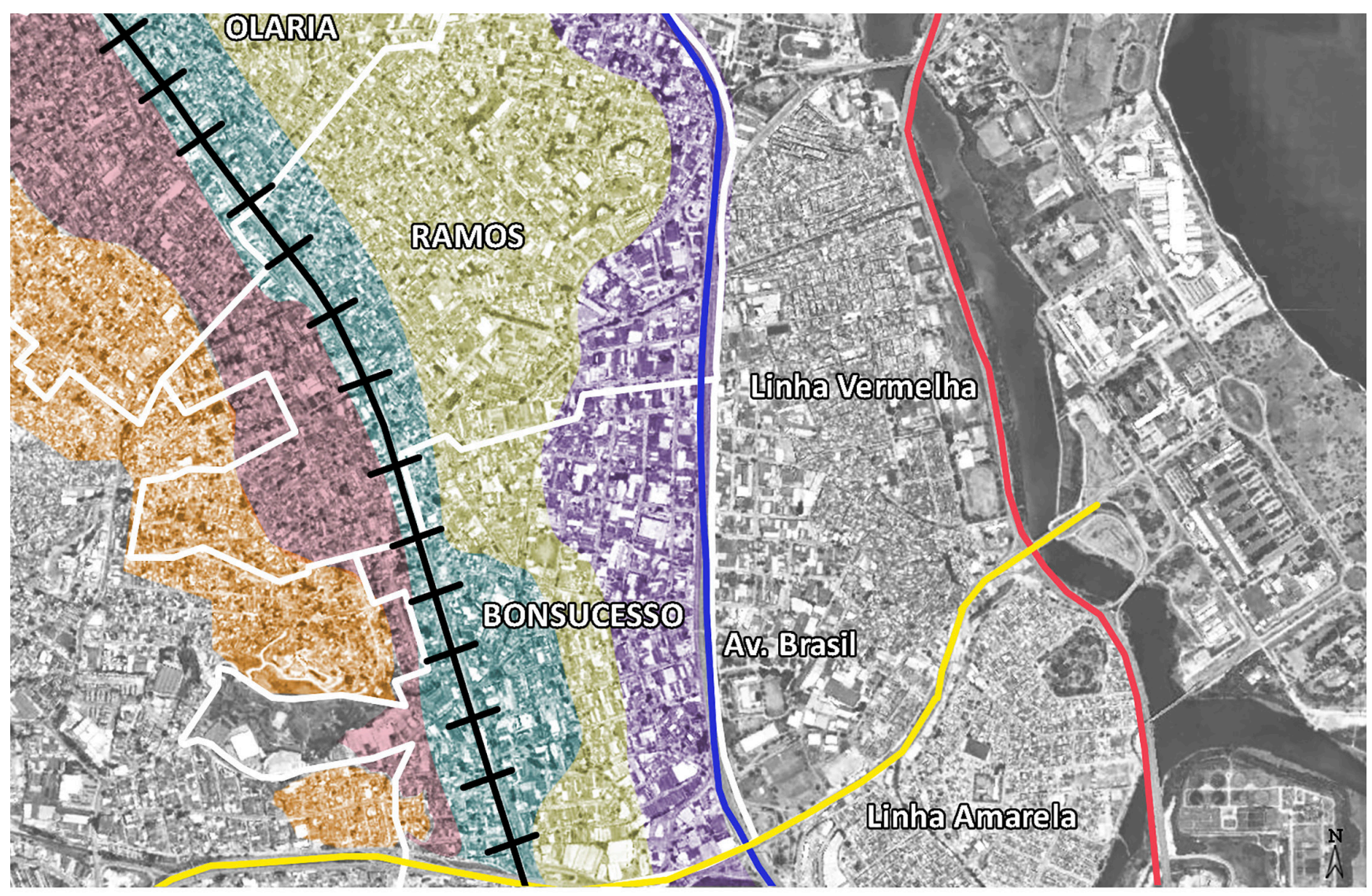
LEGENDA:

$\begin{array}{ll}\text { Ocupação em favelas } & \text { Residências baixas pontuadas por edifícios altos } \square \text { Residências baixas } \\ \text { Residência + Comércio } \square \text { Edifícios industriais }\end{array}$
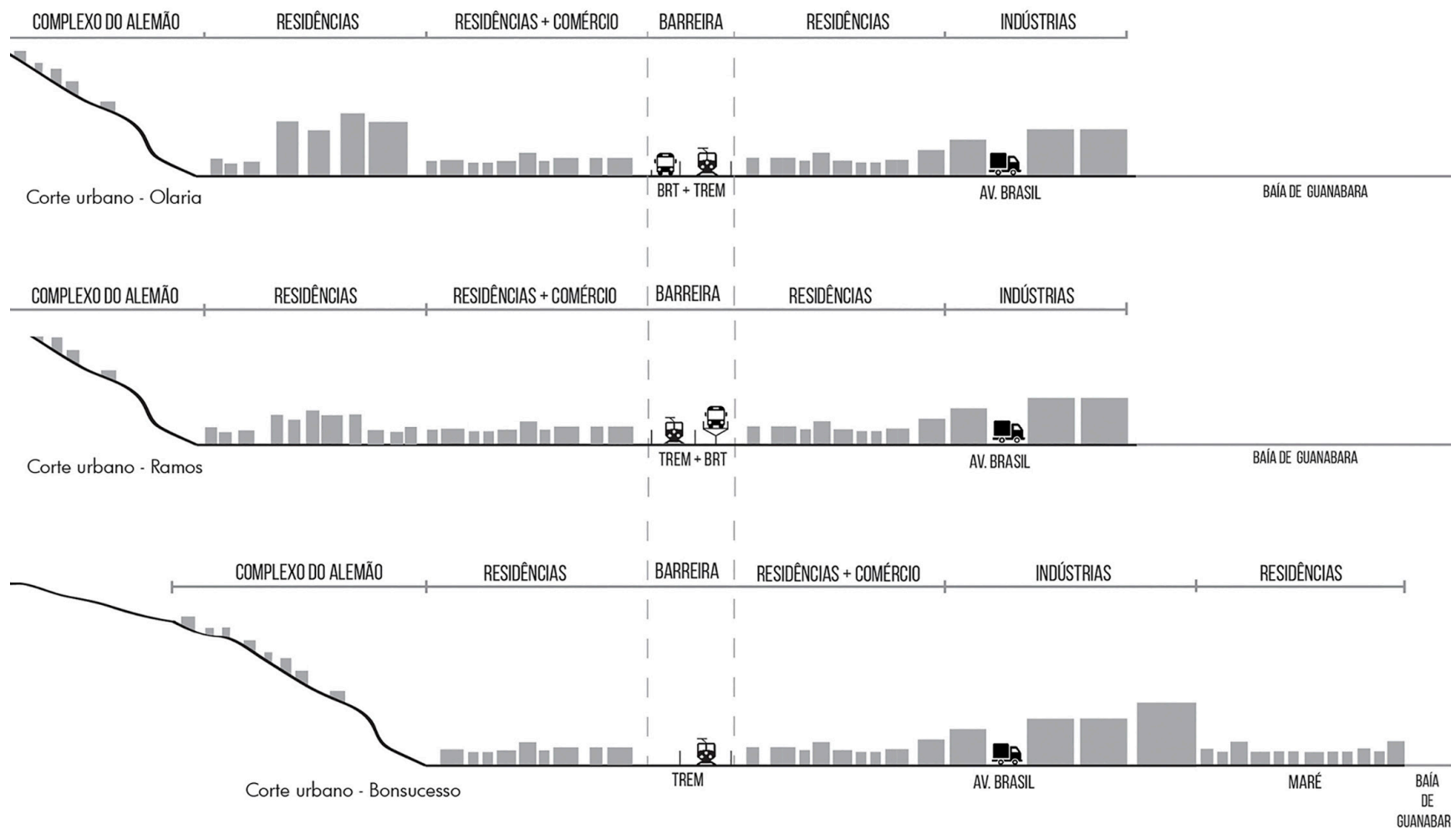


\section{AS SINGULARIDADES EFÊMERAS}

Figura 2

Detalhe de ortofoto da cidade do Rio de Janeiro, mostrando

subúrbios de Olaria, Ramos e Bonsucesso, e respectivos cortes urbanos atravessando

linha férrea.

Fonte: Caroline

Oishi e Lucas

Libonati Cury se caracterizassem pela regularidade da trama urbana e qualidade espacial dos espaços públicos resultantes de pequenas praças e reserva de áreas para equipamentos comunitários.

De fato, são inúmeros os arruamentos que apresentam essas características, promovidos por proprietários de terras nas primeiras décadas do século $X X$, e os loteamentos, promovidos por companhias industriais ou imobiliárias a partir do final dos anos 1920, possíveis de serem identificados nos processos administrativos da época até hoje vigentes. Neste contexto, observam-se como singularidades, situações efêmeras que se aproveitam da trama regular, das generosas calçadas e de pequenas praças, assim como de equipamentos comunitários instalados em amplos terrenos, permitindo ampliar o desempenho de atividades.

A efemeridade nas singularidades suburbanas observadas em Olaria, Ramos e Bonsucesso, difere em diversos aspectos daquelas relatadas em muitos trabalhos sobre arquitetura e urbanismo efêmeros (Balem, 2017; Fontes, 2013; Rosa, 201 I), referidas muitas vezes como 'micropráticas' ou 'urbanismo tático'. Nos subúrbios cariocas não se trata de criar estruturas para abrigar apropriações eventuais, protagonizadas por grupos alternativos ou movimentos locais, visando transformá-las em cenários artísticos, recreativos ou experimentais, mas de espontaneidades da cultura tradicional, promovidas por diversos agentes locais identificados com grupos sociais do pequeno capital ou mesmo vulneráveis, voltadas para lidar com necessidades básicas do dia-a-dia.

Deste modo, nas situações suburbanas efêmeras, não se trata de intervenções da ordem da manifestação ou denúncia, como se colocam muitas das arquiteturas transitórias identificadas como causas de 'antiplanejamento' ou contrárias ao 'planejamento modernista' (Brenner, 20 | 6). Referem-se muito mais a uma reação ou resistência ao mercado hegemônico (Certeau, 2014; Guattari \& Rolnik, 1996; Santos, 200I), uma tentativa de convivência e coexistência adaptando-se aos espaços intertisciais relegados pela 'razão dominante'. Neste processo, abrem uma perspectiva para a inclusão socioespacial urbana.

Neste sentido, possuem um caráter distinto dos exemplos de arquitetura efêmera mais comumente estudados, principalmente no que se refere às dimensões econômica e social urbana. Além disso, envolvem uma temporalidade diferenciada, pois apesar da natureza transitória, adquirem um caráter permanente pela sua constância de reinstalação. Têm ainda uma relevância extremamente expressiva no dinamismo urbano do lugar onde se situam, mesmo envolvendo intervenções de pequena escala.

Nos centros de Olaria, Ramos e Bonsucesso destacam-se pelo menos seis situações singulares que servem de referência no estudo da arquitetura e urbanismo efêmero. A mais comum dentre estas diz respeito ao transbordamento das atividades comerciais de pequenas lojas 


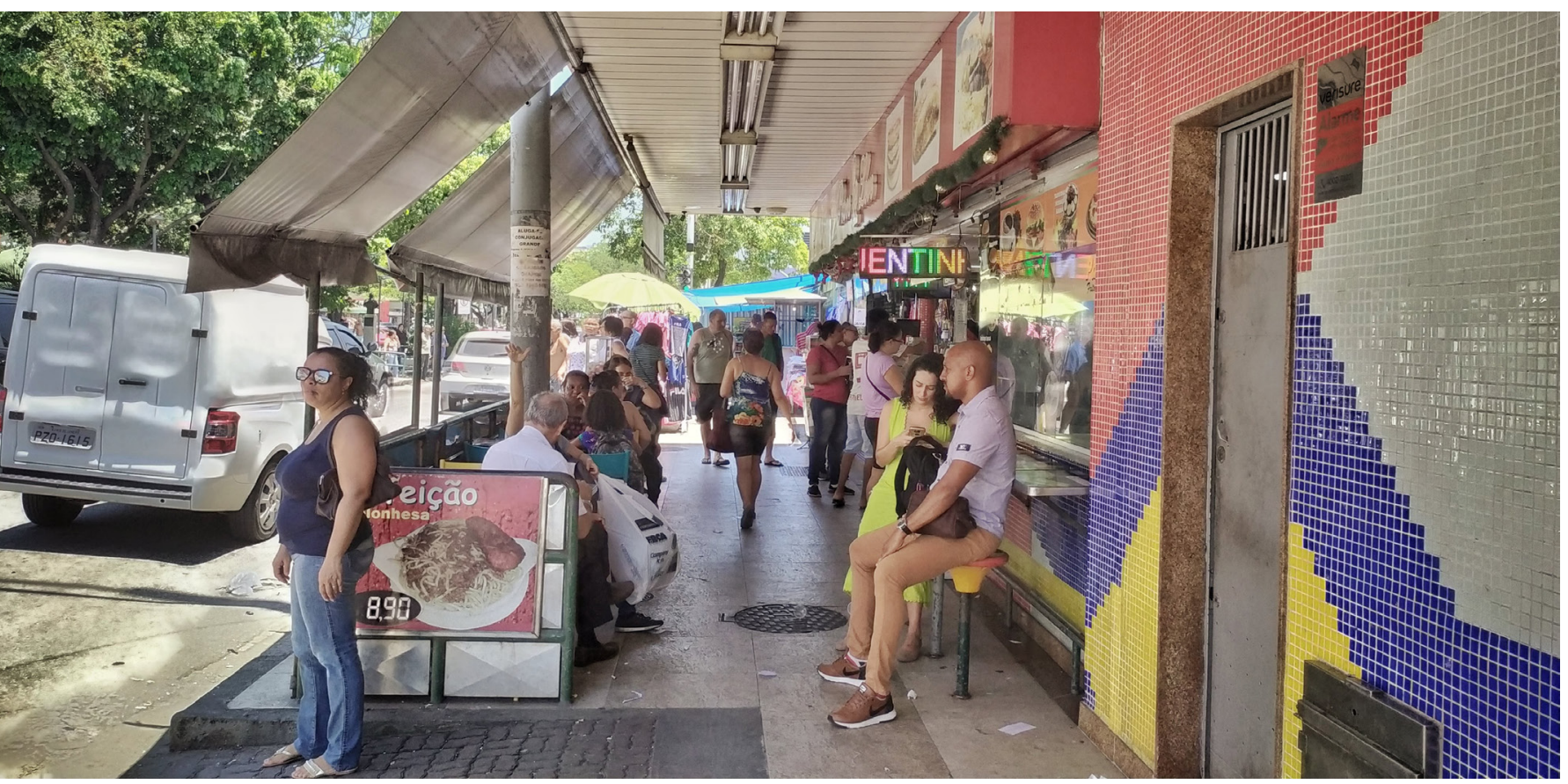

Figura 3

Transbordamento da

atividade comercial

na calçada fronteira

com reserva de faixa

para transeuntes.

Fonte: Bárbara Boy térreas nas calçadas fronteiras, criando nova configuração através da anexação de parte do espaço público como área externa ao edifício. Esse transbordamento pode se dar de duas maneiras: com a utilização apenas de espaço diminuto junto à frente do edifício, liberando o restante da calçada para os pedestres; com a utilização de faixa fronteira da calçada junto ao meio fio, deixando passagem intermediária com o edifício, para fluxo dos transeuntes [Figura 3].

Em ambos os casos, mediante dispositivos de muito baixo custo (frequentemente apenas cabideiros) conseguem ampliar a exposição das mercadorias sem aumentar o custo para o pequeno comerciante. Desta forma, cria-se um ambiente comercial favorável com o aproveitamento das calçadas generosas, propício a rivalizar com centros comerciais de grande porte, os shopping centers. Vale notar que no primeiro caso, o ambiente comercial criado é também aproveitado pela adesão na ocupação das calçadas por comerciantes informais, atraídos por sua vez pela concentração de potenciais fregueses trazidos pela comercialização de mercadorias na rua. Assim, estabelece-se de modo espontâneo, uma circulação para os pedestres, entre a exposição dos produtos do comércio formal e informal.

Na situação apresentada, em um e outro caso, ficam problemas a serem considerados pela arquitetura efêmera: o corredor para passagem dos transeuntes nem sempre se mostra suficiente nos horários do fluxo intenso, principalmente considerando a 
Figura 4

Instalação tempo-

rária de pontos de

venda atraídos pela presença de frequen-

tadores do equipa-

mento de ensino.

Fonte: Bárbara Boy profundidade dos tabuleiros ou cabideiros que expõem mercadorias; as mercadorias expostas e mesmo os vendedores, ficam vulneráveis às intempéries.

Outra situação singular relacionada ao comércio informal refere-se ao benefício mútuo trazido pela instalação temporária de pontos para venda de alimentos, atraídos pela concentração de pessoas em frente ao acesso de equipamento de grande porte, no Centro de Bonsucesso [Figura 4]. Favorece-se o vendedor ambulante e a clientela. Porém, a ambiência criada é de improvisação, podendo ser melhorada através de soluções arquitetônicas e urbanísticas.

Ainda a mencionar o comércio informal instalado nos atravessamentos subterrâneos abaixo da linha férrea, frequentemente entrada para a estação do trem, como em Bonsucesso [Figura 5]. Parede lateral da passagem subterrânea e teto se tornam suportes convenientes para exposição das mercadorias, aos quais se fixam com poucos recursos ganchos ou encostam-se prateleiras. A essas, são associados pequenos balcões, acompanhados por cadeiras. A iluminação da passagem é suficiente para clarear os pequenos estabelecimentos temporários que se aproveitam do grande fluxo de transeuntes, promovendo um sentimento de maior segurança a esses locais. A inconveniência e desafio para a arquitetura efêmera ficam por conta do risco representado por alagamentos quando de chuvas fortes.

A instalação de pontos de mototáxi em áreas próximas às estações de trem é outra situação singular percebida, especialmente nos centros

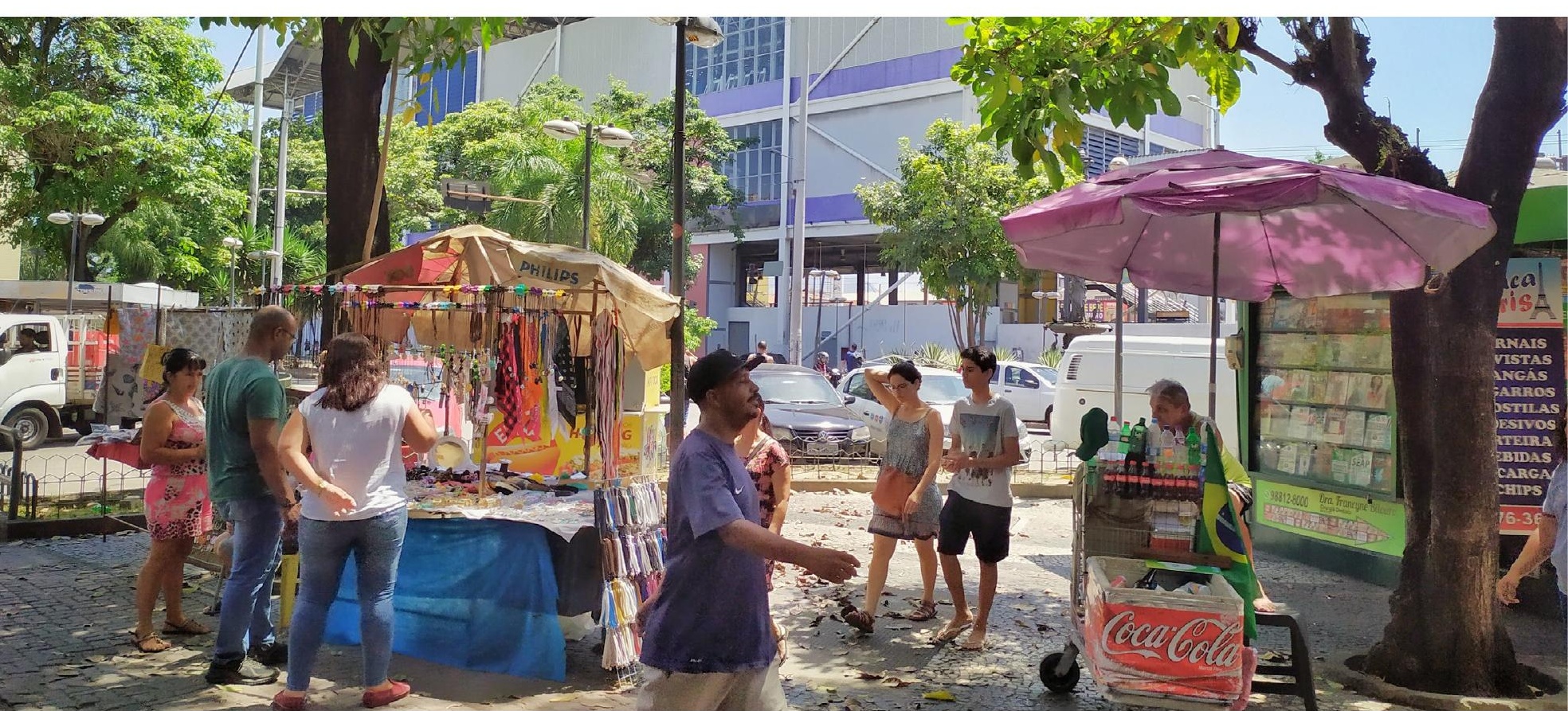




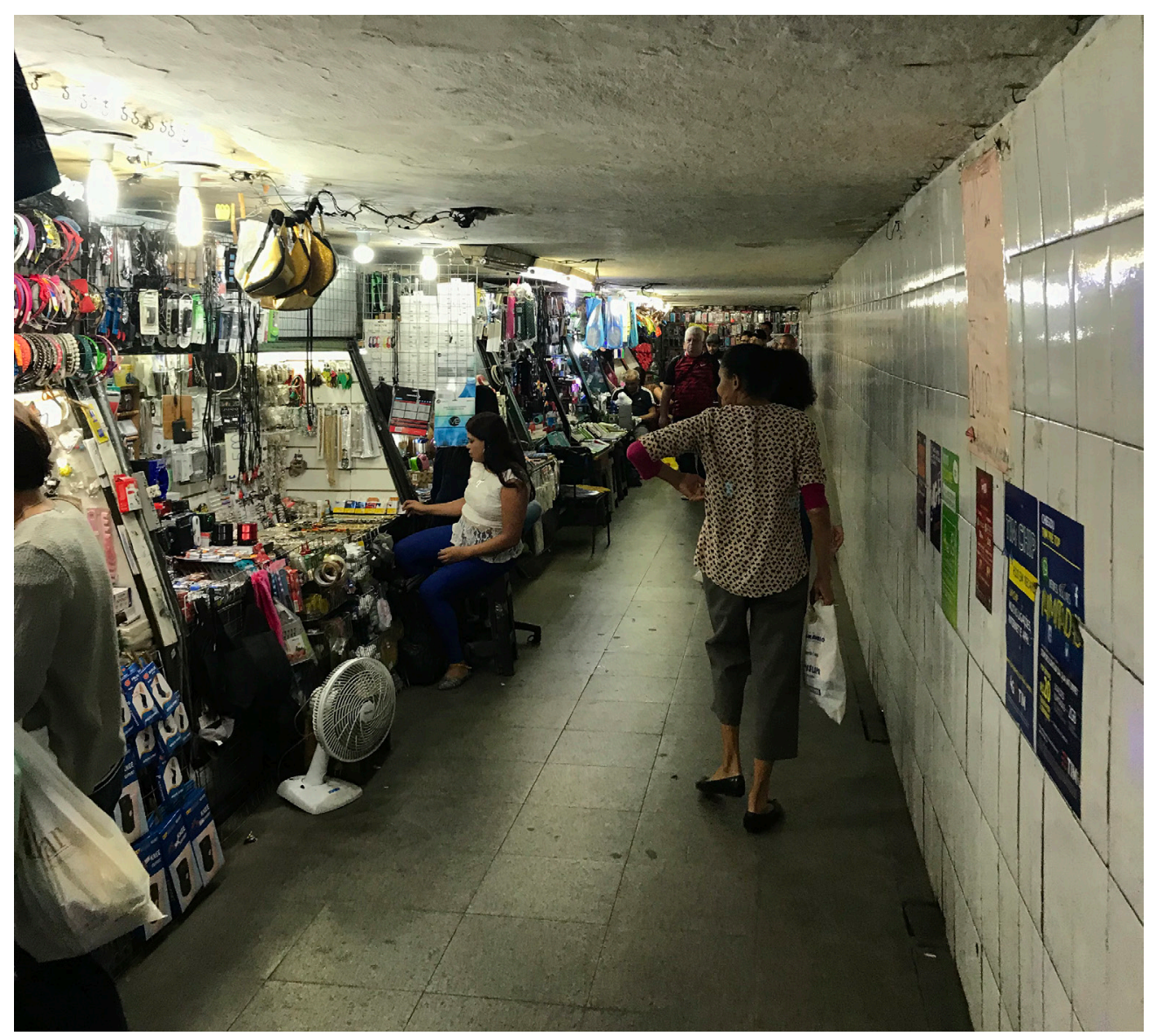

Figura 5

Comércio informal

instalado

transitoriamente

nos atravessamentos

subterrâneos abaixo

da linha férrea em

Bonsucesso.

Fonte: Lucas Libonati

Cury

de Ramos e Olaria, que se favorece da generosidade das calçadas da trama urbana. Assim, com arranjos e dispositivos muito simples - incluindo demarcação de vagas para motos, assentos rústicos individuais ou coletivos, além de telheiros compondo pequena marquise e letreiros afixados nos muros de terrenos lindeiros - parte do espaço público é apropriada por motoristas que se associam para prestar um serviço de transporte alternativo para áreas não acessíveis por ônibus [Figura 6].

Eventualmente, esses pontos se aproveitam ainda do esvaziamento das atividades comerciais, como ocorre principalmente no centro de Ramos, provocado pela intensificação da fragmentação do tecido urbano com a implantação do BRT (Bus RapidTransport) Transcarioca paralelo à linha férrea. Neste caso, o térreo do edifício no alinhamento com amplos vãos concebidos como acesso à loja, serve bem como suporte à atividade, dispensando a colocação de alguns dispositivos no espaço público [Figura 6]. De qualquer modo, a coexistência de veículos automotores, as motos, e os pedestres, nem sempre é garantida e requer soluções de arquitetura efêmera para garantia de segurança e conforto. 

Letícia Sasso
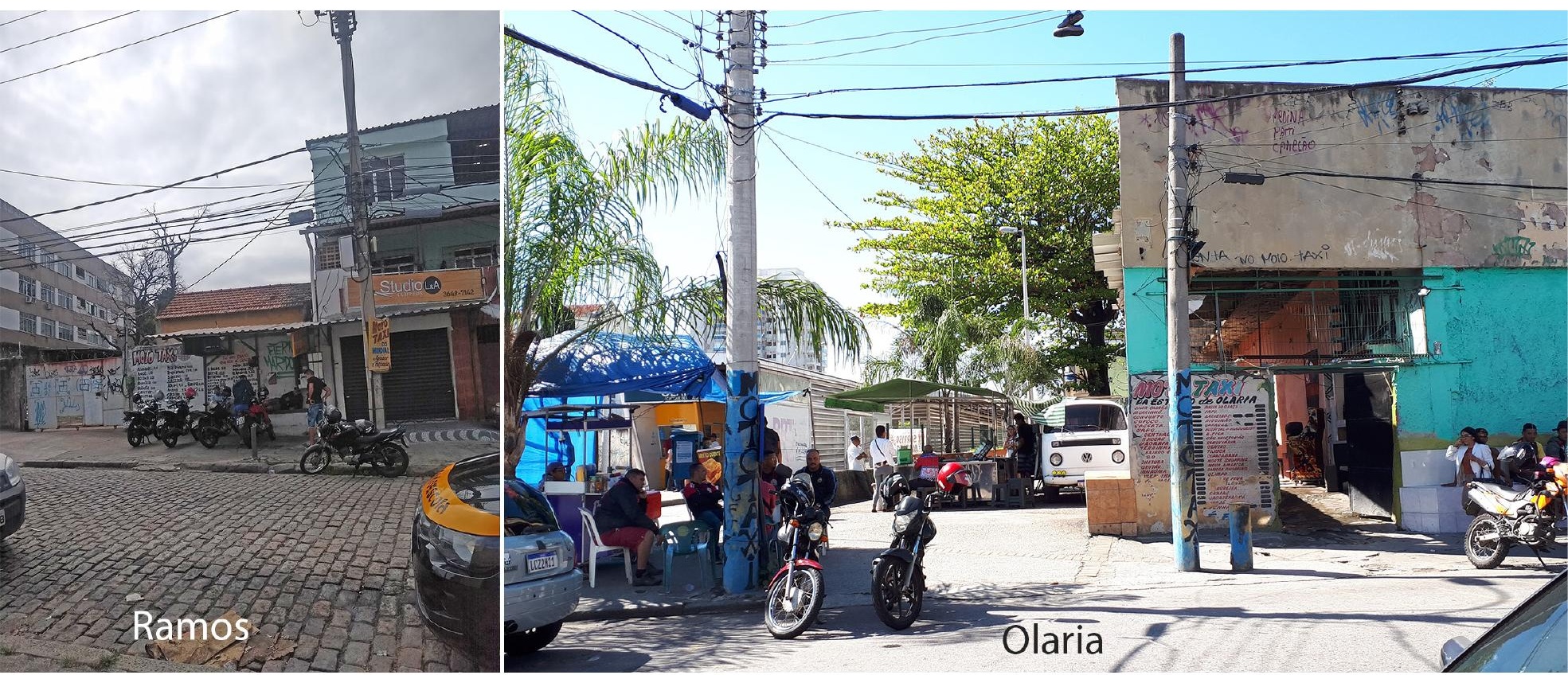

A situação singular suburbana que mais se aproxima daquelas presentes em estudos já citados sobre arquitetura ou urbanismo tático (Balem, 2017; Fontes, 2013; Rosa, 201 I) diz respeito aos eventos ao ar livre (de música e dança, exposição de arte e artesanato, feira orgânica e gastronômica), marcas da vivência do cotidiano coletivo compartilhado, sobretudo, em Olaria. Para isso, o desenho da trama urbana se revela importante, pela existência de praças, pracinhas e largos que propiciam apropriação para apresentações, encontros ao redor de mesinhas, exposição de trabalhos e mercadorias. Um exemplo emblemático é o conhecido 'Reduto Pixinguinha', evento de roda de choro, que acontece mensalmente na Praça Ramos Figueira, em Olaria. Consolida-se através da armação de uma cobertura de lona estruturada com perfis metálicos no meio da praça, na qual há bancos de concreto, e dos arranjos de mesas e cadeiras de plástico para assistentes e músicos, além de dispositivos eletrônicos e locais para preparo de comida e exposição de trabalhos e mercadorias que complementam o evento. 
Figura 7

Reduto gastronômico do 'Largo das Cinco

Bocas', na Praça

Waldir da Mota, em

Olaria.

Fonte: Laís Lucena.
Outro exemplo de referência é o popular reduto gastronômico do 'Largo das Cinco Bocas', na Praça Waldir da Mota, também em Olaria [Figura 7] cuja configuração e dispositivos utilizados assemelham-se ao anterior. $\bigcirc$ reduto ocorre semanalmente através da instalação de barracas de lona estruturadas por perfis metálicos, individualizadas por vendedores de comida, em uma das duas áreas livres públicas que existem no final da confluência de duas das vias que dão no Largo. Sobre cada uma das barracas, há dispositivos para preparo de alimentos e mesinhas e cadeiras para os frequentadores. Apesar de recentemente a Prefeitura da Cidade do Rio de Janeiro ter padronizado o tamanho e formato das barracas, e estabelecido horário de funcionamento do reduto, ainda há muito a fazer para que se transforme em ambiente de qualidade arquitetônica e urbanística. A importância dos eventos na sociabilidade e na cultura local, a par da geração de trabalho e renda para os envolvidos sem perda dos atributos da cultura local, estimulam na reflexão sobre soluções da arquitetura efêmera que possa valorizá-los.

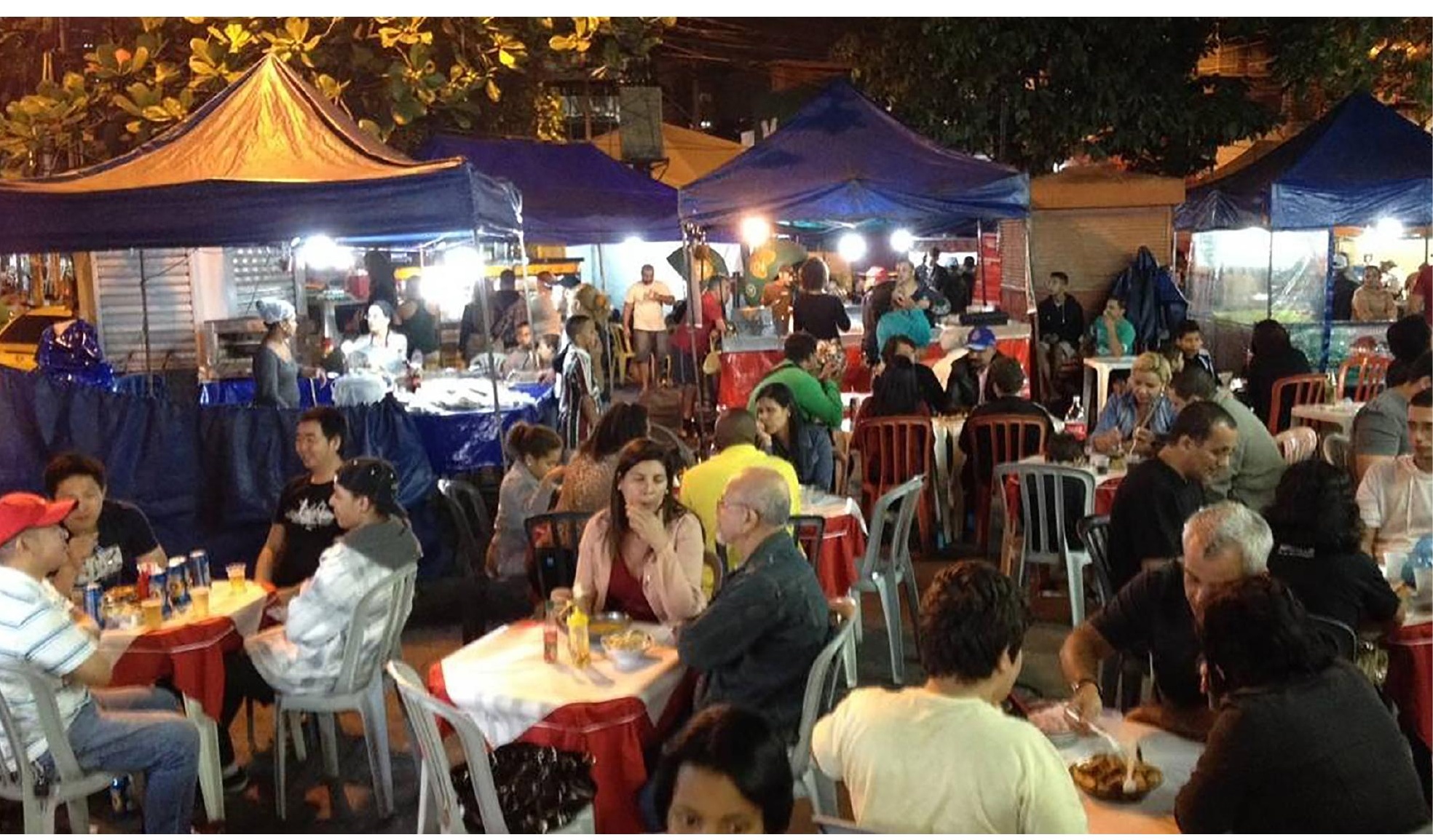




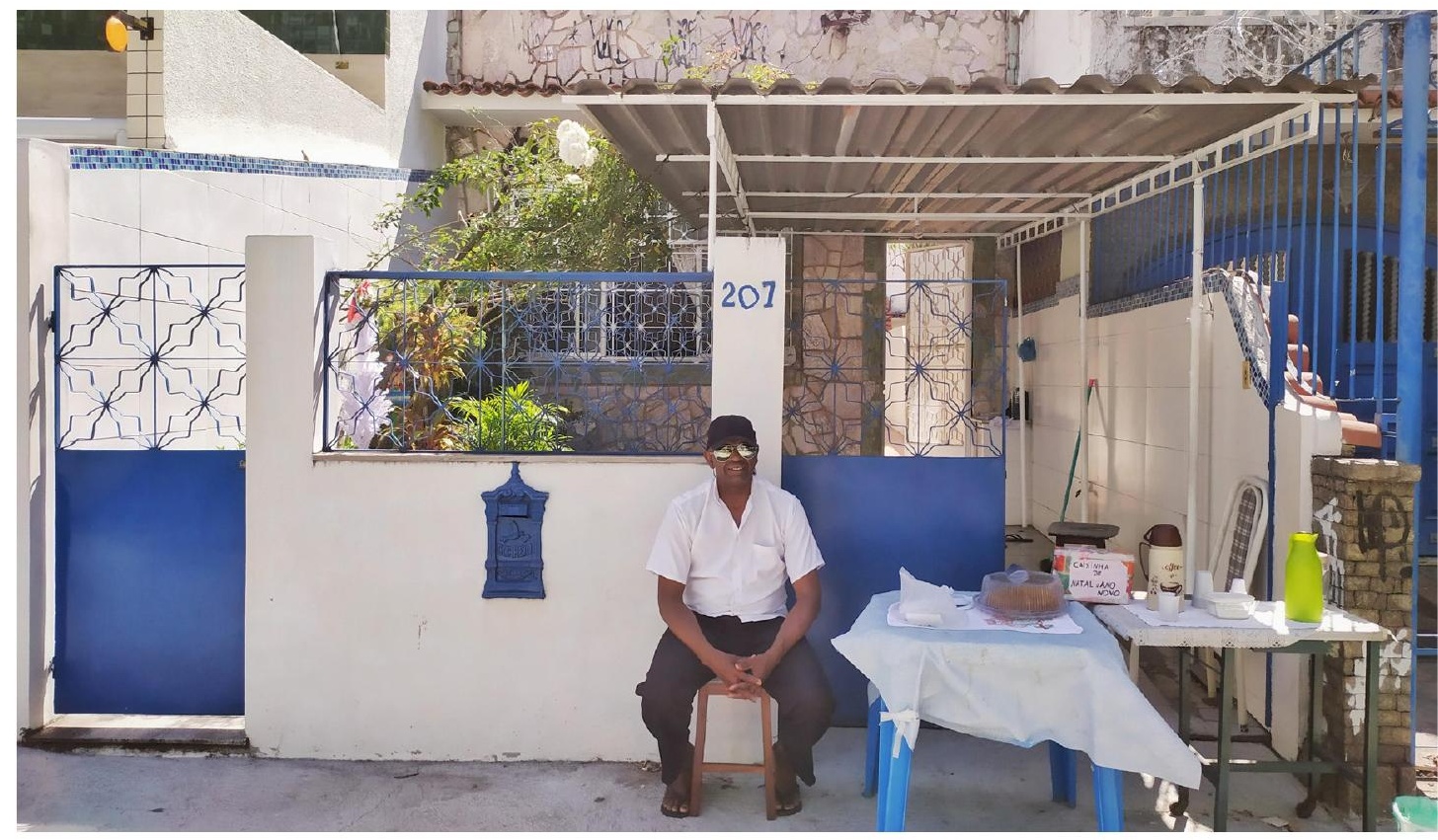

Por fim, vale citar a situação singular suburbana também muito frequente referente ao aproveitamento da fachada do edifício sob o alinhamento para agregar à moradia atividades comerciais, frequentemente, venda de alimentos [Figura 8]. $O$ peitoril da janela ou a pequena varandinha passam a ser o local de interação e atendimento ao freguês. Muitas vezes há um aproveitamento da área livre da calçada fronteira para estender a atividade comercial. A associação da fachada com o espaço público gera um espaço de trabalho, sem interferência na privacidade da moradia, que poderia ser otimizado com a aderência de soluções da arquitetura efêmera. 


\section{CONCLUSÕES}




\section{REFERÊNCIAS BIBLIOGRÁFICAS}

ALBERNAZ, M. P. Ensino e projeto urbano: uma resposta aos desafios contemporâneos. En Revista projetar - projeto e percepção do ambiente. 2018, v.3, pp.20 - 33.

ALBERNAZ, M. P. Olhares para os subúrbios da Leopoldina a partir de Bonsucesso, Ramos e Olaria. En J. S. \&, R. M. \&, T. G. Editores (Ed.). Diálogos Suburbanos: Identidades e lugares na construção da cidade. 2019b, pp. 87-114. Rio de Janeiro, RJ: Mórula Editorial.

ALBERNAZ, M. P. Suburbanização carioca: reflexos de uma identidade construída na configuração do Engenho Novo. En Urbana: revista eletrônica do Centro Interdisciplinar de Estudos sobre a Cidade (dossiê Suburbanización en Latinoamerica, 2019a, Vol. 11, N.1 [20], jan-abril/2019, pp.93-120). https://periodicos.sbu.unicamp.br/ojs/ index.php/urbana. Acesso em 15/11/2019.

AURELI, P. V. The Project of Autonomy: Politics and Architecture within and against Capitalism. New York, NY: The Princeton Architectural Press. 2008.

AURELI, P. V. The Possibility of an Absolute Architecture. Cambridge, Mass: MIT Press. 2011.

BALEM, T. Microurbanismo efêmero: entre táticas de construir e revelar a cidade. En Anais do XVII ENANPUR, 2017. São Paulo.

BISHOP, P., \& WILLIAMS, L. The Temporary City. Abingdon, Reino Unido: Routledge. 2012.

BRENNER, Neil. Seria o urbanismo tático uma alternativa ao urbanismo neoliberal? En: E-metropolis-revista eletrônica de estudos urbanos e regionais (n.27, ano 7, pp.6-18, dez 2016). Recuperado de http://emetropolis.net/system/artigos/arquivo_pdfs/000/000/201/original/emetropolis27_capa.pdf?1485998522.

CÂMARA METROPOLITANA DE INTEGRAÇÃO GOVERNAMENTAL. Caderno metropolitano 1: a retomada do planejamento. 2015. Rio de Janeiro. Recuperado de http://www.camarametropolitana.rj.gov.br/cadernos/CADERNO1.pdf

CERTEAU, M. de. A invenção do cotidiano: artes de fazer. Petrópolis, RJ: Vozes. 2014.

FONTES, A. S. Intervenções temporárias, marcas permanentes. Apropriações, arte e festa na cidade contemporânea. Rio de Janeiro: Casa da Palavra. 2013.

GORELIK, Ad. Miradas sobre Buenos Aires: Historia cultural y crítica urbana. Buenos Aires, Argentina: Siglo Veintiuno. 2004.

GUATTARI, F., \& ROLNIK, S. Micropolíticas: cartografias do desejo. Petrópolis, RJ: Vozes. 1996.

HABRAKEN, J. The Structure of the Ordinary: Form and Control in the Built Environment. Cambridge, Mass: MIT Press. 1998.

HOUAISS, A. Grande Dicionário Houaiss da Língua Portuguesa. Rio de Janeiro, RJ: Instituto Antônio Houaiss. 2001.

LYDON, M., \& GARCIA, A. Tactical urbanism. Short-term action for long-term change. Washington, DC: Island Press. 2015.

MORIN, E. Introdução ao pensamento complexo. Porto Alegre, RS: Sulina. 5a ed. 2015.

PANERAI, P. Análise urbana. Editora Universidade de Brasília, DF. 2006.

ROSA, M. Micro: Planejamento Práticas urbanas criativas (org). São Paulo, SP: Editora de Cultura. 2011

ROSSI, A. A arquitetura da cidade. Lisboa: Edições Cosmos. 1977.

SÁNCHEZ, M. L. Territorios de excepción: la CV500 como laboratorio de arquitectura. Tesis doctoral de la Universidad Politecnica de Madrid. 2015.

SANTOS, M. (2001). Por uma outra globalização: do pensamento único à consciência universal. São Paulo, SP: Record. 2001.

SOLÀ-MORALES, M. de. De cosas urbanas. Barcelona: Editorial Gustavo Gili. 2008. 